\title{
Defining 'plain language' in contemporary South Africa
}

\author{
Eleanor Cornelius \\ Department of Linguistics, University of Johannesburg, South Africa \\ Email: eleanorc@uj.ac.za
}

\begin{abstract}
Defining the concept 'plain language' has been hugely problematic since the origins of the socalled Plain Language Movement in the 1970s in the United States and elsewhere in the world. Definitions of 'plain language' abound, yet James (2008: 6) warns, in relation to plain language practitioners, that "we can't yet call ourselves a coherent field, let alone a profession, while we offer such varying definitions of what we do". Contemporary international definitions of 'plain language' are of three types: numerical (or formula-based), elements-focused, or outcomesfocused (Cheek 2010). In South Africa, protective legislation gave rise to a local definition of 'plain language' which was widely acclaimed for its comprehensiveness and practicality. From a textlinguistic angle, this article ruminates on the nature of the definition of 'plain language' in the National Credit Act (2005) and the Consumer Protection Act (2008), and critically appraises the value of the definition as a sharp and reliable conceptual tool for use by plain language practitioners - as applied linguists - in the absence of norms, standards or guidelines for the use of plain language in the consumer industry in contemporary South Africa.
\end{abstract}

Keywords: plain language, definition, readability, text processing, language policy

\section{Introduction}

Defining the concept of 'plain language' seems to be hugely problematic, and for this reason criticism is often levelled at plain language movements. 'Plain language' is often "[so] loosely defined that it can mean anything from the process of simplifying complex sentence structure to the wholesale rewriting of documents" (Schriver 1991: 1). However, there are those who argue that the vagueness and imprecision of plain language definitions do not necessarily pose a problem, as Kimble (1992: 14-15) argues in the following quote:

[...] It is no criticism that Plain English cannot be precisely, mathematically defined. Neither can 'reasonable doubt' or 'good cause'. Like so many legal terms, it is inherently and appropriately vague. And we have to settle for making it as clear and precise as possible. In fact, commentators recommend that Plain English laws not adopt the precise standards associated with readability formulas $[\ldots]$ No one expects that every contract will be perfectly 
comprehensible, but we can expect that business and government will get off dead center and try to improve them.

But some seventeen years later, Neil James refers to the confusion that has accompanied the concept of 'plain language' for decades, and points to the large variety of definitions that exist and may well impact on the work of plain language practitioners when he remarks that "[w]e can't yet call ourselves a coherent field, let alone a profession, while we offer such varying definitions of what we do" (James 2008: 6). This points to a particular need for steadfastness or some measure of undeviating constancy without which "we would [lack] a theoretical and philosophical basis for distinguishing between various disciplines" (Weideman 2011: 5).

According to James (2008: 1), apart from definitional problems, there is also some confusion as to the place of 'plain language' in the wider field of communication. Drawing on Robert Craig's (1999) work on seven distinct communication traditions, James (2008: 1) argues that the rhetorical tradition may offer the most useful paradigm for dealing with communication problems that are experienced in, for instance, legal domains. The rhetorical tradition focuses on communication as practical discourse. 'Plain language' as a cultural discipline, with dimensions that are "characteristically human [and take the form of] the logical, the historical, the lingual, the social, the juridical" (Weideman 2011: 5), is not dissimilar to rhetorics, as both apply to the same contexts. Rhetorics practitioners usually prefer methods that place the audience of any public discourse at the centre in order to reach practical outcomes.

'Plain language' and rhetorics also share the same processes and methodologies, and it is these common aspects that are especially significant. The five canons of rhetorics, as identified by the philosopher Cicero (James 2008: 3), are still important in plain language work: invention relates to content and its accuracy, completeness and the logical construction of arguments; arrangement relates to structure and organisation, and the effective sequencing of information in a text's structure according to the purpose of the text; style relates to expression (including word choice), sentence construction and length, and tone; delivery originally related principally to the verbal presentation of discourse, but in recent times it also relates to design issues such as typography, layout and other visual elements; and memory related historically to techniques to memorise long discourses or stretches of text, but we now have storage systems such as databases, help files, content management systems, etc., that essentially serve the same purposes. Although the focus of some elements may have changed in modern times, they are in essence the same as those that appeared in the traditional paradigm. James (2008) points out how these elements are represented in the definition of 'plain language' in two important South African acts: the National Credit Act of 2005 (NCA) and the Consumer Protection Act of 2008 (CPA).

It is argued in this article that the success of plain language work will largely depend on how refined its conceptual tools are. The aim of this article is threefold: (i) to ruminate on the definition of 'plain language' in the NCA and the CPA (from now on referred to as "the NCA/CPA definition"), (ii) to categorise this definition in terms of the three categories of international definitions of 'plain language', and (iii) to critically appraise the NCA/CPA definition as a conceptual tool to guide plain language practitioners in their daily work. However, before the definition is discussed and appraised, it is suggested that textlinguistics, apart from rhetorics, may provide a useful theoretical framework for plain language work. 


\section{Textlinguistics as a theoretical framework for 'plain language'}

Textlinguistics, as a science of texts, investigates the ways in which texts are produced and received. In this article, a textlinguistic approach to 'plain language' is adopted as, in addition to the production process, textlinguistics also focuses on the comprehensibility of texts.

According to De Beaugrande and Dressler (1981: 3), a text is a "communicative occurrence which meets seven standards of textuality". The seven principles are cohesion, coherence, acceptability, intentionality, informativity, contextuality and intertextuality. As 'plain language' is principally concerned with successful communication without unnecessary processing difficulties for the text receiver, any definition of 'plain language' should therefore be measured in terms of these seven principles of textuality. (These principles feature in section 8 of this article, where the NCA/CPA definition is appraised in terms of its theoretical underpinnings.)

\section{The history of 'plain language' in the world}

During the second half of the $20^{\text {th }}$ century, and particularly during the $1960 \mathrm{~s}$ and $1970 \mathrm{~s}$, pressure by consumer organisations in other parts of the world gave rise to the development of the Plain Language Movement. As a result, consumers in the United Kingdom (UK) and the United States (US) became increasingly aware of their right to receive functional documents in 'plain language' (Schriver 1991: 2). Movements soon followed in Australia, Canada, Ireland, Sweden, Denmark, France, Germany, Italy, India, Singapore, Hong Kong, Papua New Guinea, and New Zealand. For a comprehensive overview, see Asprey (2010).

The biggest impetus for 'plain language' in recent times is arguably the passing of the Plain Writing Act of 2010 in the US, which was signed into effect by President Barack Obama on 13 October 2010. The objective of this Act is to improve effectiveness and accountability in state agencies through clear communication that the public can understand and use (United States of America 2010: [1]). The Act defines 'plain language' as "writing that the intended audience can readily understand and use because that writing is clear, concise, well-organized, and follows other best practices of plain writing" (Center for Plain Language 2010: [1]).

The long history of 'plain language' around the world, and the development of 'plain language' movements in different parts of the world, inevitably gave rise to a multitude of definitions.

\section{International definitions of 'plain language'}

Myriad 'plain language' definitions have been suggested worldwide by individuals, organisations, associations, government agencies, etc. Probably the most widely cited definition of 'plain language'/'plain English' is the 1987 definition from the Law Reform Commission of Victoria in Australia (in Cheek 2010: 13). This definition also echoes the five canons of rhetorics outlined in section 1 of this article:

'Plain English' involves the use of plain, straightforward language which avoids these defects [listed earlier] and conveys its meaning as clearly and simply as possible, without unnecessary pretension or embellishment. It is to be contrasted with convoluted, repetitive and prolix language. The adoption of a plain English style demands simply that a document be written in a style 
which readily conveys its message to its audience. However, plain English is not concerned simply with the forms of language. Because its theme is communication, it calls for improvements in the organisation of the material and the method by which it is presented. It requires that material is presented in a sequence the audience would expect and helps them to absorb it. It also requires that a document's design be as attractive as possible in order to help readers find their way through it.

The International Plain Language Working Group, consisting of representatives and experts from the US, the UK, South Africa, New Zealand, Canada, Sweden, Portugal, Mexico, Hong Kong, Belgium and Australia, analysed a large number of definitions and divided these definitions into three ideal definition types, following James (2008). Definitions that essentially contain a list of guidelines for plain language writing were also considered. The three categories of definitions are (i) numerical or formula-based definitions, (ii) elements-focused definitions, and (iii) outcomes-focused definitions (Cheek 2010).

\subsection{Definitions focusing on numerical aspects}

Definitions in this category focus on specific elements that determine the readability of a text, such as word and sentence length, number of syllables, paragraph length, font size, etc. Mathematical formulas (such as the Flesch Reading Ease test, the Flesch-Kincaid Index, the Coleman-Liau Index, and the Gunning Fog Index) are applied to texts to measure readability and comprehensibility, and to link this to the reading skills of text recipients at a particular level of education (Bormuth 1966, Davison and Kantor 1982, Anderson and Davison 1988, Bruce and Rubin 1988, Zakaluk and Samuels 1988, and Jansen and Lentz 2008). An example would be the readability formulas which are included in the Microsoft Office Word and Outlook packages, two of which are described below (Microsoft Office 2015).

The Flesch Reading Ease test is the first example of a mathematical formula which may be applied to texts in order to determine their readability and comprehensibility. This test rates text on a 100-point scale where the higher the score, the easier it is to understand the document. For most standard files, the desired score would be between 60 and 70 . The formula is: $206.835-$ $\left(1.015 \times \mathrm{ASL}^{1}\right)-\left(84.6 \times \mathrm{ASW}^{2}\right)$.

A second example of a mathematical formula used for the same purpose is the Flesch-Kincaid Grade Level test. This test rates text on a US school-grade level. For most documents, the desired score would be approximately 7.0 to 8.0 , where a score of 8.0 means that an eighth grader can understand the document. In this case, the formula is: $(.39 \times \mathrm{ASL})+(11.8 \times \mathrm{ASW})-15.59$.

There are a number of advantages and disadvantages attached to the use of formulas such as these. Cheek (2010: 5) lists a number of the advantages:

- Formulas are easy to use and computer software is available.

- No writing expertise is required.

- Formulas provide an objective standard.

\footnotetext{
${ }^{1}$ Average sentence length (the number of words divided by the number of sentences).

${ }^{2}$ Average number of syllables per word (the number of syllables divided by the number of words).
} 
- Formulas indicate whether a text is easy or difficult to read.

However, the disadvantages identified by a number of researchers, in addition to Cheek (2010: 5-6), far outweigh the advantages:

- Formulas are very basic as they take only elements such as word and sentence length into consideration.

- Formulas cannot conclusively and determinedly indicate whether a document is easy to read.

- Formulas can be misleading or simply be wrong.

- Formulas do not indicate what makes a document difficult to read and therefore do not provide guidance on how the document can be improved.

- Formulas do not provide information about different target readerships, except for grade level or number of years of schooling.

- Readers' prior (or domain) knowledge, as well as their ability or inability to draw conclusions or to make complex inferences, are not taken into account (Jansen and Lentz 2008: 7).

- Formulas do not take into consideration structural markers on higher text levels, overall text organisation, and the nature of human language processing (Anderson and Davison 1988: 23).

- The application of formulas as a guideline for text production (where the producers of documents write to fit the formula) may lead to unnatural documents that may be even more difficult to understand than the original complex version. Formulas should only be used as tools for assessment to determine the readability of already existing documents (Bruce and Rubin 1988: 13).

- Formulas do not consider the motivation, interests, purpose, and social and cultural background and context of text producers and receivers (Bruce and Rubin 1988: 8, 19), and ignore differences in language users' decoding skills (Anderson and Davison 1988: 49).

Formulas provide mostly textual information, but no information about the writing and reading processes in which writers and readers engage. The Plain Language Working Group (Cheek 2010) therefore also considered definitions that are not "definitions" in the pure sense of the word, but are much rather a set of guidelines. In this way, the writing process is, to a certain extent, also brought to bear in the quest to define 'plain language' as a concept.

\subsection{Definitions focusing on writing guidelines}

This type of definition takes as a point of departure those text production techniques that aim at clarity, readability and comprehensibility, and often take the form of a list of writing guidelines. Elements-focused definitions, according to Cheek (2010: 8), are not definitions in the true sense of the word, as "they [...] serve to set out a more complete set of elements that plain language practitioners work with". Aspects that are focused on typically include issues of structure, design, content and vocabulary.

Two examples of elements-focused definitions are reproduced here. The first example dates back to 1887 (McKay, cited in Cheek 2010: 7): 
Good drafting says in the plainest language, with the simplest, fewest, and fittest words, precisely what it means.

The second example takes the form of a list of questions, used by the Plain Language Commission (2011) in the UK, to determine whether a document meets the requirements of the so-called "Clear English Standard".

\section{Purpose}

- Is the purpose obvious or stated early and clearly?

\section{Content}

- Is the information accurate, relevant and complete, anticipating readers' questions and answering them?

- Are essential technical terms explained or defined?

- Is a contact point stated for readers who want to know more?

\section{Structure}

- Is the information well organised and easy to navigate through, with appropriate headings and subheadings?

- Is there appropriate use of illustrations, diagrams and summary panels?

\section{Style and grammar}

- Is the style appropriate for the audience, with a good average sentence length (say 15 to 20 words), plenty of active-voice verbs, and reasonably short paragraphs?

- Is the document free of pomposity, verbosity and officialese (no aforesaids, notwithstandings, herebys, adumbrates, commencements and inter alias)?

- Is the text grammatically sound and well punctuated?

- Is capitalisation consistent in text and headings?

- If there is a contents page, are its headings consistent with those in the text?

\section{Layout and design}

- Does the document look good?

- Is the type easily readable and is there enough space between lines of type?

- Is there a clear hierarchy of headings and spaces?

The following advantages are associated with elements-focused definitions (Cheek 2010: 6):

- They are wider in their application and use compared to readability formulas or numerical definitions.

- They are more likely to accurately reflect a document's readability.

- They provide guidance as to how a document's readability can be enhanced.

- A document can be revised for a particular target readership according to the guidelines these definitions provide. 
Some disadvantages are also noted (Cheek 2010: 6):

- It is more difficult to follow [the elements-focused] approach and it is more time-consuming.

- Extensive judgement and text production skill are required.

- No numerical outcome of a document's success is indicated.

Redish and Rosen (1991: 83) point out that guidelines are merely suggestions, whilst rules prescribe:

Guidelines distill research and good practice into chunks of useful advice. Guidelines, however, do not replace a writer's good judgment or the writer's understanding of the writing process. [...] A writer or a team of writers can develop rules to implement a guideline within a specific context.

If guidelines are translated into measurable goals, the end result would be a readability formula. Style guidelines, such as "use the active instead of the passive voice" and "sentences should preferably be shorter rather than longer", are not inflexible rules. Rules are rigid whereas guidelines require or accept the use of good judgement; as such, guidelines often contradict one another, creating a particular tension. For example, replacing a nominalisation with a less densely packaged construction, such as an object or action verb, will result in a longer sentence (as more words are used). The judgement of the plain language practitioner should determine the best course of action when such tension arises.

\subsection{Definitions focusing on the outcome of the reading process}

Outcomes-focused definitions aim at determining how well readers can understand and use a text. The focus is not purely on the linguistic aspects of the text, but also on visual elements that may influence the readability and reception of a text. One aspect that is brought to bear in this category relates to evaluation or testing - of whatever nature - of the usability and success of a text. The following three definitions are examples of outcomes-based definitions:

A communication is in plain language if the people who are the audience for that communication can quickly and easily:

- find what they need

- understand what they find

- act appropriately on that understanding.

Redish (1985, in Cheek 2010: 8)

A well written text in plain language $[. .$.$] is one which enables the intended$ audience, whether expert or lay, to comprehend and use the text effectively.

Schriver (1991: 4)

[Plain language use is the] writing and setting out of essential information in a way that gives a cooperative, motivated person a good chance of understanding the document at first reading, and in the same sense that the writer meant it to be understood.

Cutts (1996, in Cheek 2010: 9) 
According to Cheek (2010: 6), the following are advantages of outcomes-based definitions:

- These definitions enhance the likelihood of producing documents that are easy to use.

- As these definitions involve testing, they are able to produce some statistical measure.

- Outcomes-focused definitions respond to variances between target readerships.

- These definitions provide guidance on how to improve a document.

A number of disadvantages are also cited by Cheek (2010: 6):

- These definitions constitute a more difficult approach to improving the quality of a document.

- Following an outcomes-based approach may be time-consuming and expensive.

- Testing a document may be impractical; documents are often produced under immense time pressures, leaving little time for building in a testing phase.

Often a single definition may display characteristics of two, or sometimes even all three, definition types. The International Plain Language Working Group proposes the following definition (Cheek 2010: 5) that is characteristic of the third definition type:

A communication is in plain language if it meets the needs of its audience - by using language, structure, and design so clearly and effectively that the audience has the best possible chance of readily finding what they need, understanding it, and using it.

In section 7, the local definition of 'plain language', as contained in the NCA and the CPA, is categorised in terms of these three definition types. However, before the definition is categorised and analysed from a textlinguistic perspective, a brief description of the development of 'plain language' in South Africa is provided.

\section{The relatively short history of 'plain language' in South Africa}

In South Africa, advocacy for 'plain language' is a relatively recent phenomenon. Before 1994, the use of 'plain language' was not a priority (Viljoen and Nienaber 2001: 9). In more recent years, however, consumer protection in South Africa provided a strong impetus for "plain language' in the form of legislation, most notably the National Credit Act 34 of 2005 (NCA) and the Consumer Protection Act 68 of 2008 (CPA). Burt (2009: 42) comments as follows on recent developments in the consumer industry:

For plain language advocates around the world, having so many plain language laws may sound like winning the first, second and third prize all at once. Part of the reason is that, in South Africa, law as the tool for change is the only way to expedite remedies for the inequities of the past. We didn't have a culture embedded in the rule of law where unwritten constitutions govern how people 
behave. We didn't have a history of respect for human rights - a general morality based on seeing others as equals. We didn't have a process for lobbying for change.

\section{Defining plain language in contemporary South Africa}

The right of access to information in plain language is regarded as a basic human right in both Acts. In terms of sections 64(2) of the NCA and section 22(2) of the CPA, consumer documents must be in plain language, to the extent that:

[...] an ordinary consumer of the class of persons for whom the notice, document or visual representation is intended, with average literacy skills and minimal experience as a consumer of the relevant goods or services, could be expected to understand the content, significance and import of the notice, document or visual representation without undue effort, having regard to -

(a) the context, comprehensiveness and consistency of the notice [...];

(b) the organisation, form and style of the notice [...];

(c) the vocabulary, usage and sentence structure of the notice [...]; and

(d) the use of any illustrations, examples, headings or other aids to reading and understanding.

\section{Categorising the local definition}

The definition of 'plain language' in the NCA and CPA displays characteristics of both elements-focused and outcomes-focused definition types, and also similarities with the rhetorical canons distinguished by Cicero (in James 2008: 3). The definition contains guidelines for readability and clarity in the form of a list of writing techniques and linguistic devices to be employed, but also suggests that testing could be an important consideration. Testing can indicate to what extent an ordinary consumer is able to understand effortlessly the "content, significance and import" of a consumer document. For this reason, the role that testing and evaluation can play in providing access to information should not be underestimated. Empirical testing and statistical results can inform the guidelines according to which plain language practitioners should write or rewrite consumer documents for lay audiences. Testing can eliminate subjectivity and guesswork that may be inherent in the phrase "that an ordinary consumer $[\ldots]$ could be expected to understand".

\section{The local definition from a textlinguistic perspective}

In this section, the NCA/CPA definition of 'plain language' is analysed from a textlinguistic perspective. Implications for plain language practitioners are pointed out at appropriate junctures.

\subsection{Cohesion}

Cohesion refers to those "surface-structure features of an utterance or text which link different parts of sentences or larger units of discourse, e.g. the cross-referencing function of pronouns, articles and some types of adverb" (Crystal 2003: 81). Different cohesive devices, such as reference, substitution, ellipsis, conjunction and lexical cohesion, can be employed in a text to create connections between components of the surface text. The NCA/CPA definition requires 
that the plain language practitioner ensures that consumer documents are drafted or revised in such a way that an ordinary consumer "could be expected to understand the content, significance and import of the notice, document or visual representation without undue effort" (Republic of South Africa 2005, 2008). The same warning that Carstens (2003: 29) issues to text editors is valid for plain language practitioners:

If a text editor does not have the necessary linguistic knowledge (in other words, if he does not know about syntactical patterns, cannot apply anaphoric constructions or if he does not have the ability to make semantic links), he cannot effectively use these means to create a text that binds all the textual elements together.

The NCA/CPA definition reminds the plain language practitioner to pay attention to the "vocabulary, usage and sentence structure of the notice $[\ldots]$ ".

Cohesion helps with comprehension as it makes connections between sentences, and the propositions they carry, more explicit. Donnelly (1994: 96) explains further that "[...] cohesion makes textual connections explicit to a listener or reader". Plain language practitioners should employ the different cohesive devices referred to earlier to ensure effective communication and optimal comprehension, thereby lowering the amount of cognitive energy the ordinary consumer has to expend whilst reading. The NCA/CPA definition therefore acknowledges the important role of cohesion in textual communication.

\subsection{Coherence}

Coherence, according to Renkema (2004: 49), refers to "the connection that is brought about by something outside the text". The role of prior knowledge during text processing is now widely accepted. That "something outside the text" referred to by Renkema is what coherence is about:

[Coherence] involves the study of such factors as the language users' knowledge of the world, the inferences they make, and the assumptions they hold, and in particular of the way in which coherent communication is mediated through the use of speech acts.

(Crystal 2003: 81)

It is often the case that ordinary consumers do not have the necessary prior knowledge to cope with a complex legal document, and the NCA/CPA definition also makes provision for this. The definition refers to the possibility that a consumer may have minimal experience of the relevant goods and services, and therefore may not have entered into consumer agreements before. Coherence involves "[...] the ways in which the components of the textual world, i.e. the configuration of concepts and relations which underlie the surface texts, are mutually accessible and relevant" (De Beaugrande and Dressler 1981: 4, original emphasis).

If the ultimate goal is that the consumer should be able to understand a text without much effort, the plain language practitioner should employ those devices and techniques afforded by the language concerned to ensure that textual relationships are made explicit and that the actual links between words and sentences are clear. The consumer document must, of necessity, display textual unity and a logical underlying structure without any mental gaps. Reference in 
the NCA/CPA definition to issues such as comprehensiveness, consistency, organisation, form, style, vocabulary, usage and sentence structure affirms the importance of coherence and also cohesion in a consumer document. The plain language practitioner is also reminded to consider other aids for understanding, alluding to the impact of document design issues on comprehension and readability.

\subsection{Intentionality and acceptability}

The producer has the intention that the document $\mathrm{s} /$ he produces forms a coherent and cohesive unit. If no intention can be recognised or identified, the sequence of words will be "not unlike the penmanship practice of elementary school pupils" (Renkema 2004: 50). The reader should recognise the intention of the text producer and accept the document as a textual occurrence with a message that needs to be communicated.

Following De Beaugrande and Dressler (1981) and Bell (1991), the NCA/CPA definition confirms text processing as consisting principally of two skilled activities, namely production (synthesis) and reception (analysis). The first part of the definition focuses on the interpersonal relationships between the participants in the communicative event. There is a producer and a receiver (the consumer) of a notice, document or visual representation. The definition therefore suggests a real reader that the plain language practitioner should have in mind during the production and/or revision process. This underscores the importance of compiling a profile of the intended target audience.

\subsection{Informativity}

Informativity refers to the extent to which information presented in the text is known (and therefore old) or unknown (therefore new), or whether the information is predictable or unpredictable. According to Bell (1991: 168), the balance between known and predictable information or new and unpredictable information will determine to what extent the text is readable and interesting. High levels of informativity place a higher demand on cognitive processing. The NCA/CPA definition warns against this with the phrase "[...] to understand $[\ldots]$ without undue effort".

The NCA/CPA definition proposes that the information in a consumer document should be in line with the linguistic competence of the target audience. Furthermore, the definition implies that readers (consumers) should be able to construct meaning from the text, possibly upon first reading (i.e. "without undue effort"). In the case of a dispute regarding the use of plain language (or lack thereof), a court will have to determine whether the consumer "could be expected to understand the content, significance and import of the notice, document or visual representation". Knight (2006: 21 ) is of the opinion that the following three questions are relevant: (i) Can the consumer understand the content of the document? (ii) Can the consumer understand the credit arrangements in the document?, and (iii) Can the consumer understand the consequences the document has for the credit arrangements (and other aspects that may be of importance to the consumer)? These questions lead us to the next principle, namely contextuality. 


\subsection{Contextuality}

Contextuality refers to "the factors which render a text relevant to a current or recoverable situation of occurrence" (De Beaugrande and Dressler 1981: 163). When the appropriateness of a text is evaluated, it is necessary to determine where the text will be used and what the function or purpose of the text is in that situation. Additionally, Carstens (2003: 26) notes that "[...] the quality and effect of the communication is determined by the contextual knowledge the participants share".

The NCA/CPA definition provides contextual information in the form of a profile of the reader (a context of use is therefore created for the consumer document): the reader is a member of a class of persons (i.e. consumers) for whom the notice, document or visual representation is intended. The average literacy skills of this class of persons are also of particular importance as is the fact that they have minimal experience as consumers.

This characterisation of the target readership is useful to the plain language practitioner as particular contextual information is provided. Two types of real world experience are alluded to in the NCA/CPA definition: reading experience and consumer experience. On this basis, the plain language practitioner can work on two assumptions: firstly, that the consumer has some reading experience, and secondly, that the consumer is not an experienced debtor.

\subsection{Intertextuality}

Intertextuality refers to "the ways in which the production and reception of a given text depends upon the participants' knowledge of other texts" (De Beaugrande and Dressler 1981: 182).

The NCA/CPA definition captures the essence of this principle by indicating that, in all probability, the reader has "minimal experience as a consumer". This means that readers are vulnerable consumers with little or no experience of credit agreements or knowledge of similar documents. Therefore, these consumers cannot rely on stored knowledge and, as a result, high levels of mediation are required. It is these consumers in particular that should enjoy the protection of the NCA and CPA.

Alternatively, some consumers may have some experience of consumer documents, but these experiences may have been negative, resulting in high levels of alienation due to the presentation of information (for instance, using extreme registers or information on the second and third levels of informativity). Information presented in the text should be carefully selected and possibly scaffolded in one way or another to bridge any gaps in the stored knowledge of the reader. The NCA/CPA definition "[...] reject[s] any notion of a text-based conception of communication and recognize[s] that meaning is not simply lying on the page, waiting to be absorbed, but rather is created in the minds of readers applying themselves to a document and the symbols encoded upon it" (Knight 2006: 20-21).

As is evident from the discussion in this section, the value of the definition of 'plain language' in the NCA and the CPA lies in its theoretical underpinnings. Knight (2006: 21) rightly asserts that the value of this definition is in its recognition that a consumer document is not a static artefact; the definition focuses on the interpersonal dynamics of written human communication. 


\section{Problems with the 'plain language' definition}

Although the NCA/CPA definition is firmly grounded in textlinguistic theory, as indicated earlier in this article, some problems need to be pointed out. These problems relate mainly, but not exclusively, to factors external to the definition itself, such as issues of multilingualism and literacy. If these problems are not addressed, the optimal use of plain language in the consumer industry will not become a reality as envisaged by the NCA and CPA.

\subsection{Language realities in South Africa}

The hegemonic position of English seems to feed into the notion that 'plain language' means plain English. However, according to Alberts (2001: 92), a large portion of the South African population can only be reached through the use of indigenous languages, yet English is still used in virtually every public and private domain. In relation to law and commerce, Kahn (2001: 3) warns that "only Afrikaans, and then to a diminishing extent, owing largely to the concentration of blacks on English, has a place in law and commerce. [...] The black languages are virtually non-existent in law and commerce". The NCA/CPA definition of 'plain language' ignores the linguistic landscape in South Africa, and provides no guidance on how multilingualism and multiculturalism should be dealt with in the consumer industry.

The NCA provides in section 63(1) that "[a] consumer has a right to receive any document that is required in terms of this Act in an official language that the consumer reads or understands, to the extent that is reasonable having regard to usage, practicality, expense, regional circumstances and the balance of the needs and preferences of the population ordinarily served by the person required to deliver that document".

Section 63(2) provides as follows:

If the producer of a document that is required to be delivered to a consumer in terms of this Act is, or is required to be, a registrant, that person must -

(a) make a submission to the National Credit Regulator proposing to make such documents available in at least two official languages; and

(b) offer each consumer an opportunity to choose an official language in which to receive any document, from among at least two official languages as determined in accordance with a proposal that has been approved by the National Credit Regulator.

However, as in the case of the language provisions in the Constitution (Act 108 of 1996), a back door is left wide open with the phrase "to the extent that is reasonable". Burt (2009: 42) asks a very important question in relation to issues of language and literacy: "If a document is provided only in English and the consumer can only read Sesotho, will the consumer still be of 'average literacy'?". Schriver and Gordon (2010: 36-37) warn that research is mainly conducted in and on English, and that this practice yet again serves only the needs of those who speak English as a first language:

Another quite different problem with the existing research is that it has been conducted mainly in English with native English speakers. Basic and applied research needs to be conducted with populations across many languages and 
cultures. It may be that some issues of plain language are unique to particular countries and/or particular languages.

The issue of literacy in the various South African languages is of crucial importance. There is a pressing need to reconcile language policy (in the broad sense) with plain language policy (in the narrow sense).

\subsection{Determining average literacy}

A second problem relates to the concept of 'average literacy' in the NCA/CPA definition. The definition allows for two interpretations of this concept: firstly, the reference may apply to the average literacy rate of all consumers in South Africa, and secondly, the phrase may refer to the average literacy of the intended target group of the particular consumer document. The latter interpretation suggests that the literacy rates of the target group must be determined in advance, most probably by using a literacy test of some sort. The majority of literacy tests in South Africa measure academic literacy as opposed to general literacy, and are also mainly available in English. ${ }^{3}$ Determining the average literacy of a particular target audience is thus highly problematic and without proper guidance, the work of the plain language practitioner may be reduced to mainly guesswork.

\subsection{The gap between theory and practice: Language policy}

The third problem relates to the importance and the preparedness of the language profession to comply with the provisions of the plain language legislation. Plain language work requires specialist knowledge, and draws on theoretical insights gained from textlinguistics, cognitive science, reading research, sociolinguistics (language variation and language planning), and so forth.

'plain language', as an ultimate goal, can only succeed if plain language capacity exists and if plain language practitioners are able to reconcile plain language theory with plain language practice. Presently, there is no conclusive evidence to suggest that expertise currently exists on the scale that is required by the plain language provisions in the two Acts. As a result, a number of legal practitioners (i.e. lawyers) are now entering the market and working as plain language practitioners. However, this begs the question: do these legal practitioners have the required theoretical knowledge of text processing to successfully revise complex consumer documents for increased access to information for vulnerable consumers with limited literacy skills? The same question may be asked in relation to those plain language practitioners who indeed have a solid theoretical foundation in the discipline of linguistics but lack legal, financial or similar knowledge (i.e. knowledge of the subject matter of the complex consumer document).

If answers to these questions are not found, and the required capacity is not developed, companies, organisations and institutions may merely pay lip service to the plain language provisions in the NCA and CPA in an effort to avoid hefty penalties. Fines for non-compliance to the provisions of the CPA may be as high as $10 \%$ of the company's annual turnover or R1 million, whichever amount is the greatest (Marus 2010: 24).

\footnotetext{
${ }^{3}$ Personal communication: Prof. A. Carstens on 12 August 2011.
} 


\subsection{Lack of norms and standards for assessment}

Lastly, the NCA/CPA definition creates a vacuum by not addressing issues related to plain language standards for assessment purposes. The Acts provide that the credit regulator (in the case of the NCA) or the consumer commission (in the case of the CPA) "may publish guidelines for methods of assessing whether a notice, document or visual representation satisfies the requirements of subsection (1)(b)". There is, however, still no indication of the methods that will be used to assess consumer documents. Burt (2009: 44) warns as follows:

Plain language initiatives driven only by compliance run the risk of implementing superficial, objective criteria which do not necessarily give information that truly helps the consumer to make informed decisions.

From the late 1970s, the goal of plain language laws in some states in the US was to ensure that citizens were able to understand the rights, obligations and limitations of any agreement they entered into. The only (or best) way to determine comprehension is to test the consumer's ability to understand and use a document, but this may be expensive and time-consuming. As a result, lawmakers decided to identify alternative methods by providing guidelines for writing (see section 4.2) to ensure ease of use and comprehension.

The criteria that are used to assess a document's readability should be a good substitute for testing. Moreover, the criteria should not place an undue or additional burden on the drafters of consumer documents, as such a burden would discourage compliance in the consumer industry (Bowen, Duffy and Steinberg 1991: 22-23). Bowen, Duffy and Steinberg (1991: 23) warn as follows:

Since the goal of plain language legislation is to ensure that a citizen who enters into a consumer contract can readily determine what his or her rights and obligations are, the type of legislation which best meets those goals should be determined. (By 'readily determine' we mean that the individual can read through the contract, pointing to and describing the rights and responsibilities that are essential in the agreement.)

The same authors suggest that answers to the following questions be sought when a document is assessed in terms of 'plain language':

(i) Does plain language legislation help (or protect) the consumer and are simplified agreements easier to understand and use?

(ii) Which language, layout and design features facilitate ease of use and promote comprehension the most?

(iii) Which design and organisation features distinguish excellence from averageness?

(iv) Which legal provisions have the biggest influence on the comprehensibility and usability of documents, with the lowest cost to the consumer industry? 
In contemporary South Africa, with the implementation of the provision of the CPA still a fairly recent occurrence, there is little guidance on the issue of evaluation and assessment. The lack of norms and standards creates tension in the consumer and the language industry alike.

\section{Concluding remarks}

The implementation of protective legislation in South Africa, such as the NCA and the CPA, creates conducive conditions for optimal communicative success. Among others, these Acts highlight the importance of plain language and clear communication, particularly in documents that are given to consumers (such as binding contracts). It is a fundamental right of consumers to understand the contracts they enter into and it is the duty of the stronger party, e.g. a credit provider, to ensure that vulnerable consumers are able to understand, without undue effort, the risks and obligations under the contract. The role of the (plain) language practitioner here cannot be overemphasised.

There is no longer a place for the traditional style of legal drafting in the South African consumer industry. The development of new registers to convey important consumer information is now becoming increasingly pressing, especially since low literacy levels correlate with low levels of command of the extreme register associated with legal texts.

As pointed out, plain language practitioners in South Africa have a useful tool to approach their work with, in the form of the definition of 'plain language' in the NCA and the CPA. This definition draws on elements-focused and outcomes-focused approaches to 'plain language', and furthermore is firmly grounded theoretically.

The problems highlighted in the latter part of this article, however, need to be addressed to ensure optimal communication in the consumer industry and other sectors of the economy.

\section{References}

Alberts, M. 2001. Plain language in a multilingual society. In F. Viljoen and A. Nienaber (Eds.) Plain legal language for a new democracy. Pretoria: Protea. pp. 89-118.

Anderson, R.C. and A. Davison. 1988. Conceptual and empirical bases of readability formulas. In A. Davison and G.M. Green (Eds.) Linguistic complexity and text comprehension: Readability issues reconsidered. New Jersey and London: Lawrence Erlbaum Associates. pp. 23-54.

Asprey, M.M. 2010. Plain language for lawyers. Fourth edition. Sydney: The Federation Press. Available online: http://www.federationpress.com.au/PDFs/AspreyCh4Exp.pdf (Accessed 20 July 2011).

Bell, R.T. 1991. Translation and translating. Theory and practice. London and New York: Longman.

Bormuth, J.R. 1966. Readability: A new approach. Reading Research Quarterly 1(3): 79-132. 
Bowen, B.A., T.M. Duffy and E.R. Steinberg. 1991. Analyzing the various approaches of plain language laws. In E.R. Steinberg (Ed.) Plain language: Principles and practice. Detroit: Wayne State University Press. pp. 19-29.

Bruce, B. and A. Rubin. 1988. Readability formulas: Matching tool and task. In A. Davison and G.M. Green (Eds.) Linguistic complexity and text comprehension: Readability issues reconsidered. New Jersey and London: Lawrence Erlbaum Associates. pp. 5-22.

Burt, C. 2009. Laws set the framework for plain language in South Africa. Clarity 62: 41-45.

Carstens, A. 12 August 2011. Personal communication with Prof. Adelia Carstens. Pretoria, South Africa.

Carstens, W.A.M. 2003. Text linguistics and text editing. In K. Van de Poel (Ed.) Text editing: From a talent to a scientific discipline. Antwerp Papers in Linguistics 103: 22-35.

Center for Plain Language. 2010. Plain Writing Act of 2010. Available online: http://centerforplainlanguage.org/plain-writing-laws/plain-writing-act-of-2010/ (Accessed 18 July 2011).

Cheek, A. 2010. Defining plain language. Clarity 64: 5-15.

Crystal, D. 2003. A dictionary of linguistics and phonetics. Fifth edition. Malden, MA: Blackwell Publishing.

Davison, A. and R.N. Kantor. 1982. On the failure of readability formulas to define readable texts: A case study from adaptations. Reading Research Quarterly 17(2): 187-209.

De Beaugrande, R.A. and W.U. Dressler. 1981. Introduction to text linguistics. London: Longman.

Donnelly, C.E. 1994. Linguistics for writers. Albany: State University of New York Press.

James, N. 2008. Defining the profession: Placing plain language in the field of communication. Paper read at the $3^{\text {rd }}$ international Clarity Conference, 20-23 November 2008, Mexico City.

Jansen, C. and L. Lentz. 2008. Hoe begrijpelijk is mijn tekst? De opkomst, neergang en terugkeer van de leesbaarheidsformules. Onze Taal 77(1): 4-7.

Kahn, E. 2001. Plain English in law and commerce in South Africa. Clarity 46: 3-5.

Kimble, J. 1992. Plain English: A charter for clear writing. Thomas M. Cooley Law Review 9: 1-58.

Knight, P. 2006. Clarity for South Africa's credit consumers. Clarity 56: 19-21.

Marus, L. 2010. Gobbledygook has gotta go. Enterprise Risk 4(10): 24. 
Microsoft Office. 2015. Test your document's readability. Available online: https://support.office.com/en-us/article/Test-your-documents-readability-0adc0e9a-b3fb4bde-85f4-c9e88926c6aa (Accessed 12 June 2015).

Plain Language Commission. 2011. Plain-English editing and writing-skills training: Helping you clarify your web and printed communications. Available online: http://www.clearest.co.uk/ $\underline{\mathrm{id}=30}$ (Accessed 7 July 2011).

Redish, J.C. and S. Rosen. 1991. Can guidelines help writers? In E.R. Steinberg (Ed.) Plain language: Principles and practice. Detroit: Wayne State University Press. pp. 83-92.

Renkema, J. 2004. Introduction to discourse studies. Amsterdam and Philadelphia: John Benjamins Publishing Company.

Republic of South Africa. 1996. Constitution of the Republic of South Africa 108 of 1996. Available online: http://www.justice.gov.za/legislation/constitution/SAConstitution-webeng.pdf (Accessed 9 October 2015).

Republic of South Africa. 2006. National Credit Act 34 of 2005. Available online: http://www.justice.gov.za/mc/vnbp/act2005-034.pdf (Accessed 9 October 2015).

Republic of South Africa. 2009. Consumer Protection Act 68 of 2008. Available online: http://www.thenct.org.za/NCTDocs/founding-legislation/f8d6f6aa-994d-4305-b3d0ea056416bbd0.pdf (Accessed 9 October 2015).

Schriver, K. 1991. Plain language for expert or lay audiences: Designing text using protocol-aided revision. Technical Report No. 46. Pittsburgh, PA: Centre for the Study of Writing, Berkeley, CA.

Schriver, K. and F. Gordon. 2010. Grounding plain language in research. Clarity 64: 33-39.

United States of America. 2010. Plain Writing Act of 2010. Available online: http://www.gpo.gov/fdsys/pkg/BILLS-111hr946enr/pdf/BILLS-111hr946enr.pdf (Accessed 19 August 2011).

Viljoen, F. and A. Nienaber. (Eds.) 2001. Plain legal language for a new democracy. Pretoria: Protea.

Weideman, A. 2011. A framework for the study of linguistics. Pretoria: Van Schaik.

Zakaluk, B.L. and S.J. Samuels. (Eds.) 1988. Readability. Its past, present, and future. Delaware: International Reading Association. 